\title{
Rat sexual behavior: Photographic analysis of the intromission response'
}

\author{
Gordon Bermant 2 \\ UNIVERSITY OF CALIFORNIA, BERKELEY
}

\begin{abstract}
Abstraet
High-speed photography of electrically monitored rat sexual behavior suggested that the intromission response may be analyzed into two components: a dete $\mathrm{cti}$ ion component, in which the male makes a variable number of very rapid shallow thrusts around and eventually into the vaginal opening, and a stimulation component, which consists of a single deep thrust into the vagina followed immediately by rapid and vigorous withdrawal and dismount. A suggestion is offered which relates the form of the behavior to the presumed method of penile receptor stimulation.
\end{abstract}

\section{Problem}

During copulation a male rat mounts and penetrates the female several times (usually between 8 and 15) before a mount with penetration and ejaculation finally occurs. The time intervals between the penetrating contacts (intromissions) are on the order of 0.5-1.0 min., while the duration of each intromission is approximately $300 \mathrm{msec}$. (Pierce \& Nuttall, 1961; Carlsson \& Larsson, 1962). While it seems obvious that the stimulation of the penis during the very brief penetrating contacts must in some way be responsible for the eventual orgasmic response and seminal emission, the details of the process which bring the male to ejaculation are not at present understood (Beach, 1956; Bermant, 1964).

The brevity of the intromission response precludes detailed observation by normal means. In the past three techniques have been employed to increase the precision of the analysis: high-speed photography, which results in a "slow motion" effect (Stone \& Ferguson, 1940), a ventral viewing angle, which permits direct observation of the genital area (Beach \& Rabedeau, 1959), and electrical monitoring of penetrating contact, which permits automatic measurement of intromission duration (Pierce \& Nuttall, 1961). The present study represents an attempt to study the intromission response by combining all of these techniques.

\section{Method}

Sexually experienced Long-Evans rats between 150250 days old served as subjects. The males lived in group cages in the experimental room under a reversed 12-hr. on, 12-hr. off light cycle.

The testing compartment was a semi-elliptical cage 11 in high, 20 in across the face and 12 in deep at the maximum. Wooden and clear Plexiglas floors were used at different times during the experiment. A 1/16 in wide slit was cut in the floor parallel to the front of the cage, 7 in from the front edge.
During testing each member of the copulating pair wore a small safety-pin electrode. The male's electrode was placed through the scruff of the neck. A light wire soldered to the safety-pin ran out through the top of the cage. The female's electrode was attached ventrally, through the skin over the sternum. From her electrode a light wire ran out through the slit in the bottom of the cage. Wired in this fashion, the animals served as a switch in series with a six-volt battery and a twotransistor DC amplifier. ${ }^{3}$ When the circuit was closed, 6-watt lamps in the cage ceiling and on the underside of the transparent floor were operated by current passing through the poles of a quick-closing relay actuated by the output of the amplifier. The sensitivity of the system was set such that only the moist contact produced by the insertion of the penis into the vagina was sufficient to operate the relay, thereby turning on the lamps.

The camera used in this study was a Paillard Bolex H16 reflex. Film speed for the analysis was 64 frames per sec.

Both lateral and ventral viewing angles were used. For the lateral view the lens was aimed directly into the open face of the observation cage. For the ventral view the lens was aimed at the surface of a plane mirror mounted at an appropriate angle beneath the transparent floor of the observation cage.

Stimulus females were brought into behavioral estrus by subcutaneous injections of $0.1 \mathrm{mg}$ estradiol benzoate approximately $72 \mathrm{hr}$. before use and $1.0 \mathrm{mg}$ progesterone approximately $6 \mathrm{hr}$. before use. ${ }^{4}$

A male and estrous female were first adapted separately to the observation cage by allowing access under minimal illumination for several minutes. The male's electrode was then attached and he was allowed several more minutes of adaptation. The female's electrode was then attached, and she was introduced into the cage.

The films were inspected under two conditions. First, they were projected onto a screen at a speed of $16 \mathrm{fps}$, which produced a fourfold dilation in time. Secondly, they were viewed using a standard film editor. A frameby-frame analysis was made by noting the positions of the animals as observed on each frame.

\section{Results}

Results are based on the performance of 6 males who effected a total of 42 intromissions at angles with respect to the lens that permitted accurate analysis. Thirty were filmed with lateral view and 12 with ventral view. Films of 11 ejaculations and 15 mounts without intromission were also analyzed. 
Soon after the male is mounted upon the female with his forepaws clasped around her flanks, he begins a series of very rapid, shallow thrusts. As observed by Stone and Ferguson, the number of these "preliminary" thrusts varies from intromission to intromission. The males in this study showed, on the average, between 3 and 4 shallow thrusts per intromission, with a range from 0 to 10 .

The important point is that in almost every case the onset of the overhead light was correlated with the end of this set of thrusts, not with the beginning. This means that there was very little, if any, moist tissue contact for the duration of most of this part of the sequence.

Almost immediately following light onset the form of the thrusting pattern changed. The series of shallow thrusts was followed invariably by a deep thrust or lunge (42 out of 42 cases). In 39 of these cases the single deep thrust was followed immediately by a backward movement of the forequarters, a rising up and pushing away on the hind feet, and the beginning of the characteristic paw flip (the form of the dismount causes maximum contact of the dorsum of the penis against the female's vagina and perineum). In two of the three remaining cases two thrusts were seen following light onset; in the third case three thrusts were observed.

Analysis of 15 mounts without penetration suggested two reasons for failure to penetrate; (1) Failure of erect penis to contact the vaginal opening, and (2) lack of sufficient erection to allow vaginal contact in spite of a series of vigorous shallow thrusts.

The ejaculation response, in contrast to intromission, consisted of as many as six or seven deep thrusts preceding the single great convulsive thrust and slow, spasmodic "after-thrusts" correlated with seminal expulsion.

\section{Diseussion}

Stone \& Ferguson (1940) made the distinction between deep and shallow thrusts which is given here. Their film analysis, based on a lateral viewing angle, led them to conclude that all thrusting activity occurred while the penis was inserted in the vagina. Results reported here suggest that this is seldom the case, although it usually appears to be with an unmonitored lateral viewing angle. And on some occasions a partial insertion is made during shallow thrusting. What is being suggested here, however, is that the primary function of the shallow thrusting stage is to locate the vagina, not to provide stimulation to the penis which will lead eventually to ejaculation. The shallow thrusts may be said to serve a detection function (cf. Beach, 1942, p. 137). Their form and frequency depend on immediate feedback. The single deep thrust and stereotyped removal pattern constitute the stimulation component of the sequence. The component is ballistic in that, once initiated, it runs its full course without major modification. Within another framework, the shallow thrusts seem classifiable as appetitive behaviors, while the single deep thrust and withdrawal together form a consummatory response.

If the bulk of the stimulation during an intromission comes from the single deep thrust and withdrawal, it may be reasonable to suppose that the stereotyped deep thrust and dismount pattern serves to maximize the amount of stimulation derived from each intromission. The form of the dismount insures maximal contact of the dorsal side of the penis with the dorsal aspect of the vaginal barrel.

Histological evidence led Beach (1952) to offer a suggestion for the mode of action of rat penile receptors during copulation. In the engorged penis cornified papillae are pressed into the dermis to form ridges running around most of the glans. The papillae are attached to deep-lying nerve endings which may be mechano-receptors. Physical displacement of the papillae leads to receptor activation. If this interpretation is correct, the friction produced by the form of the dismount pattern should serve to maximize the total amount of stimulation available during the single deep thrust and withdrawal.

Analysis of the intromission response into detection and stimulation components suggests that disruption of information from the first component will hinder performance of the second. Evidence for this effect in the rat has been found, and will be reported elsewhere.

\section{References}

$\mathrm{BEACH}$, F. A. Execution of complete masculine copulatory patterns by sexually receptive female rats. J. genet. Psychol., 1942, 60, 137-142.

BEACH, F. A. Mechanisms of hormonal action upon behaviour. In G. E. W. Wostenholme (Ed.), Ciba foundation colloquia on endocrinology, Vol. III. London: Churchill, 1952. P. 209.

$\mathrm{BEACH}$, F. A. Characteristics of masculine "sex drive." In M.R. Jones (Ed.), Nebraska symposium on motivation: 1956. Lincoln: University Nebraska Press, 1956. Pp. 1-32.

BEACH, F. A., \& RABEDEAU, R. G. Sexual exhaustion and recovery in the male hamster. J. comp. physiol. Psychol., 1959, 52, 56-61. BERMANT, G. Effects of single and multiple enforced intercopulatory intervals on the sexual behavior of male rats. J. comp. physiol. Psychol., 1964, 57, 398-403.

CARLSSON, S., \& LARSSON, K. Intromission frequency and intromission duration in the male rat mating behavior. Scand. J. Psychol., 1962, 3, 189-191.

PIERCE, J., \& NUTTALL, R. Durations of sexual contact in the rat. J. comp. physiol. Psychol., 1961, 54, 584-586.

STONE, C. P., \& FERGUSON, L. W. Temporal relationships in the copulatory behavior of adult male rats. J. comp. Psychol., 1940, $30,419-433$.

\section{Notes}

1. This research was conducted under the tenure of NSF and NIMH post-doctoral fellowships, and supported in part by NIH grant No. MH-04003, awarded to F. A. Beach.

2. Present address: Department of Psychology, University of California, Davis, California.

3. The amplifier was designed and built by Mr. Michael Saslow. 4. The hormones were supplied by Dr. R. McCormick of the Schering Corporation. 